\title{
Cochlear implant codes and speech perception in the profoundly deaf
}

\author{
GERALD S. WASSERMAN \\ Sensory Coding Laboratory, Department of Psychological Sciences \\ Purdue University, West Lafayette, Indiana 47907
}

\begin{abstract}
Cochlear implants are coming into widespread use as prostheses for profoundly deaf patients suffering from sensorineural deafness. Such patients can detect sounds when the implant electrically stimulates their remaining peripheral auditory nervous system. But useful speech recognition has not yet been achieved with either single- or multiple-channel cochlear implants. Because cochlear implants are essentially artificial receptors, the prosthetic signal provided by such implants must be coded in a form that contains the essential attributes of the sensory codes used by natural receptors. Sensory coding studies of natural receptors have indicated that the sensory code is task dependent. In particular, these studies have indicated that the sensory code for pattern recognition is the integral of the temporally dispersed receptor signal. These natural receptor data suggest that speech recognition in the profoundly deaf may be improved by incorporating an appropriate degree of temporal dispersion into the design of cochlear prostheses.
\end{abstract}

The function of sensory receptors can be studied in two ways: One way is to try to understand how natural receptors normally encode sensory information (cf. Uttal, 1973). Another way is to build artificial receptors and then study their ability to replace natural receptors. Figure 1 illustrates these two different approaches to the receptor coding problem.

Artificial cochleas are now in widespread use as prostheses for patients who have sensorineural deafness caused by hair cell disease or damage. The historical

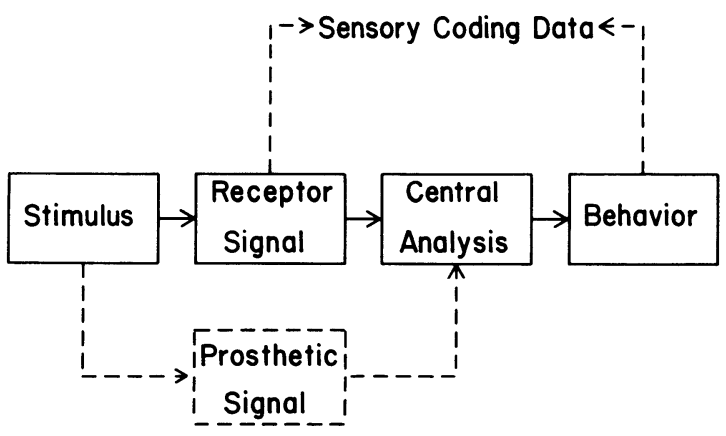

Figure 1. The natural flow of sensory information and its relation to the coding and the prosthetic research strategies. Solid boxes indicate the way in which stimulus information is normally transduced by receptors into bioelectric signals that are analyzed by the central nervous system for ultimate expression in behavior. Broken lines indicate two ways of studying the contributions of receptors to this process: The prosthetic approach builds an artificial receptor that generates an electric signal that replaces the natural sensory signal. The sensory coding approach collects data from receptors and from behavior under comparable stimulus conditions. background of the cochlear implant was reviewed by House, Berliner, Crary, Graham, Luckey, Norton, Selters, Tobin, Urban, and Wexler (1976) and Simmons (1966). A modern cochlear implant was first developed by Djourno and Eyriès (1957) and further developed by a number of other investigators including Bilger, Black, Hopkinson, and Myers (1977), Bilger, Black, Hopkinson, Myers, Payne, Stenson, Vega, and Wolf (1977), Eddington, Dobelle, Brackmann, Mladejovsky, and Parkin (1978), Hochmair, Hochmair-Desoyer, and Burian (1979), House et al. (1976), House and Urban (1973), Lawrence and Johnsson (1973), Mladejovsky, Eddington, Dobelle, and Brackmann (1974), Merzenich, Michelson, Pettit, Schindler, and Reid (1974), Michelson (1971), Pialoux, Chouard, Meyer, and Fugain (1979), Simmons (1966), Simmons, Epley, Lummis, Guttman, Frishkopf, Harmon, and Zwicker (1965), Simmons, Mongeon, Lewis, and Huntington (1964), and Walloch, DeWeese, Brummett, and Vernon (1973).

The performance of these cochlear implants is good enough that patients voluntarily seek out these devices even though they must undergo surgery. The cochlear prosthesis does allow profoundly deaf patients to obtain some acoustic information about their environment. But despite this progress, a significant problem still remains, because auditory prostheses have not yet led to any useful ability to recognize the auditory patterns used in speech communication. This is true for both single-channel implants that stimulate large sections of the cochlea with signals that represent sounds covering a large portion of the auditory spectrum (Hochmair et al., 1979; House et al., 1979), and multichannel implants that stimulate specific regions of the cochlea 
with signals that each represent a specific portion of the auditory spectrum (Eddington et al., 1978; Pialoux et al., 1979; Simmons, 1966). Patients do not reliably recognize randomly chosen words spoken to them through either type of implant.

This is not to say the artificial cochlea does not permit the deaf to extract any information at all from speech. When a limited set of words is used, patients do significantly better than chance at associating a given spoken word with the corresponding written member of the set. For example, if a written list of five to seven words is presented visually to a patient and then one of those is spoken to the patient via the cochlear implant, one finds that the patient is able to do much better than the chance level of $14 \%$ to $20 \%$. With single-channel implants, the highest performance reported in such an experimental design is 62\% (Hochmair et al., 1979). The highest performance reported with multiple-channel implants is 95\% (Pialoux et al., 1979). To my knowledge, no investigator has compared performance in such a situation between a single- and a multiple-channel version of the same prosthesis, and so it is difficult to tell whether the higher performance reported by Pialoux et al. is due to the greater number of channels or whether it is due to some other variable. Nevertheless, these results are encouraging and suggest that cochlear implants need only a small improvement to mediate ad-lib speech perception successfully.

Evidence that leads to a suggested solution to this speech recognition problem comes from sensory coding studies of natural receptors that have indicated that the natural receptor sensory code is task dependent. These studies have compared intracellular recordings taken from single receptors with the behavior of intact subjects. Problems studied have included: the problem of temporal summation, or the tradeoff between stimulus duration and intensity (Kong \& Wasserman, 1978a, 1978b; Wasserman, 1978; Wasserman \& Kong, 1975); the problem of the psychophysical function, relating sensation quantity to stimulus intensity (Wasserman, Felsten, \& Easland, 1978, 1979; Wasserman, 1981); and the problem of perceptual masking, or the effect that one stimulus has on the perception of a second stimulus (Felsten \& Wasserman, 1978, 1979a, 1979b, 1980, 1981; Wasserman, Lo, \& Easland, 1976).

The conclusion that emerged from this work was that different features of the natural receptor potential carry different information about the external environment. The feature of the receptor response (or the sensory code) that mediates performance when the subject's task is to detect the presence or absence of a stimulus turns out to be the magnitude of the initial transient peak of the receptor potential. On the other hand, the receptor sensory code that relates to behavioral competence in tasks in which the subject is asked to recognize or to identify some aspect of the stimulus (beyond merely indicating that a stimulus is present or absent) is the integral of the temporally dispersed receptor potential cumulated over a period that may be several seconds in some circumstances.

Confirmation of this interpretation of the natural receptor sensory code has recently come from studies of the sensations evoked in visual cortex by artificial electrical stimulation. In this case, detection is mediated by the initial portion of the artificial signal (Girvin, Evans, Dobelle, Mladejovsky, Henderson, Abramov, Gordon, \& Turkel, 1979), whereas identification continues to be influenced by the artificial signal for durations up to $2 \mathrm{sec}$, which were the longest employed (Evans, Gordon, Abramov, Mladejovsky, \& Dobelle, 1979). Additional corroboration comes from studies of the acoustic evoked potential: Detection performance correlates with the amplitude of the early components of the evoked potential, whereas recognition correlates with the later components, even though very brief stimuli (50 msec duration) were used (Parasuraman \& Beatty, 1980).

This coding evidence suggests that a necessary ingredient of any cochlear implant that will mediate speech perception successfully is that the prosthetic signal should simulate the temporal dispersion found in the natural receptor. But present cochlear implants have essentially no temporal dispersion at all. Figure 2 shows the essential elements of a representative cochlear implant, namely, the House-Urban stimulator. This device transduces acoustic stimuli into electrical signals by a microphone. Then this electrical copy of the stimulus is used to modulate an AM oscillator whose carrier frequency is typically near or above the upper limit of the auditory spectrum. This AM-modulated signal is applied to the cochlea via a pair of induction coils mounted on either side of the skin. The only temporal dispersion introduced by present cochlear prostheses is the dispersion attendant on the fact that the carrier frequency limits the artificial receptor's ability to follow extremely rapid changes. In most cases, this would amount to a few microseconds of dispersion.

An obvious way to incorporate temporal dispersion into existing auditory prostheses would be to add an electronic integrator to the circuit shown in Figure 2 between the microphone and the oscillator. But temporal dispersion in the natural receptor appears only in conjunction with a number of other operations, some of which are strongly nonlinear. Hence, merely adding an integrator to present prostheses would lead to a signal that would have properties very different from those of the naturally dispersed receptor signal: Adding such an integrator by itself would merely discard high-frequency acoustic information. But natural receptors select information from a particular portion of the auditory spectrum, rectify and compress these signals, and also disperse them in time (Corey \& Hudspeth, 1979; Russell \& Sellick, 1977, 1978; Sellick, 1979; Sellick \& Russell, 1979).

A modified cochlear implant that would simulate these operations of the natural auditory receptor is 


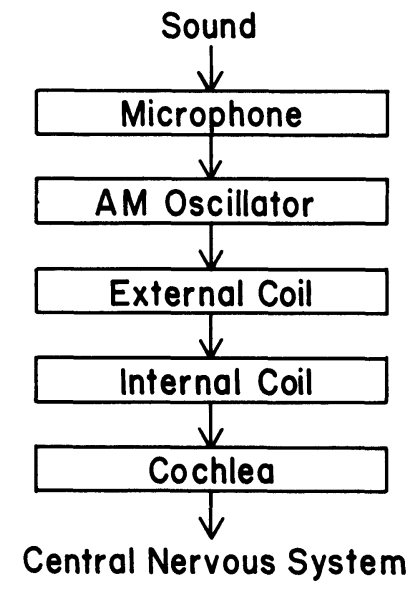

Figure 2. Block diagram of an electronic stimulator typical of those used in present cochlear prostheses. Sound is transduced into electrical signals by a microphone that modulates the amplitude of a high-frequency oscillator whose output is led to an induction coil located on the outside of the patient's skin. The external induction coil induces currents in an internal induction coil connected to a pair of wires implanted inside and outside the cochlea. Current flowing between these two wires generates neural activity in the axons of the auditory nerve.

illustrated in Figure 3. This block diagram depicts one channel of what would ultimately be a multichannel system, although an initial study might examine the performance of a single-channel version. This prosthesis includes several new elements, one of which is a rectifier, which is included because recent intracellular recordings from single auditory receptors have shown that one of their most striking properties is the extent to which they rectify the auditory signal (Corey \& Hudspeth, 1979; Russell \& Sellick, 1977, 1978; Sellick, 1979; Sellick \& Russell, 1979). Another striking property of the auditory receptor (which is shared with virtually every other known receptor) is a compressive relation between stimulus intensity and potential magnitude. Thus the proposed prosthetic rectifier would also have a compressive transfer function. The rectifier creates a dc component in the prosthetic signal, even though the acoustic stimulus has only ac components. It is the presence of this dc component that radically alters the influence of the next additional stage in the prosthesis, namely, the integrator that disperses the prosthetic signal over time. The optimal dispersion for this integrator cannot be given on the basis of information currently available. Judging from the degree of dispersion that can be observed in the above-mentioned intracellular recordings from single auditory receptors, the prosthetic signal should probably outlast the stimulus by $5-20 \mathrm{msec}$. But this parameter can be optimized by clinical research.

To be fully comparable to a natural receptor, the output of the integrator would be fed back to reduce the gain of the rectifier stage. The effect of this feedback would be to emphasize the initial transient relative to the persisting tail of the response. In coding theory terms, such feedback would favor detection at the expense of recognition. An ideal prosthesis would mediate both aspects of perception, and the amount of feedback for optimal performance in both domains would have to be set by the outcome of clinical research. The amount of feedback might even be under patient control to suit the momentary requirements of any particular situation. All of the other stages of the suggested cochlear implant are essentially the same as those used in present designs. More important, all of the suggested changes can be made in the electronics package that the patient carries externally, and none of them affects the implanted electrodes themselves. Thus, it should be possible to "breadboard" this circuit and to study its performance with patients who have already received a surgical implant, in order to optimize its circuit parameters.

It is impossible to say at the present time that this suggested artificial cochlea will definitely be sufficient to enable deaf patients to understand ad-lib speech. But one can say, on the basis of the evidence in hand, that an artificial receptor that includes an appropriate

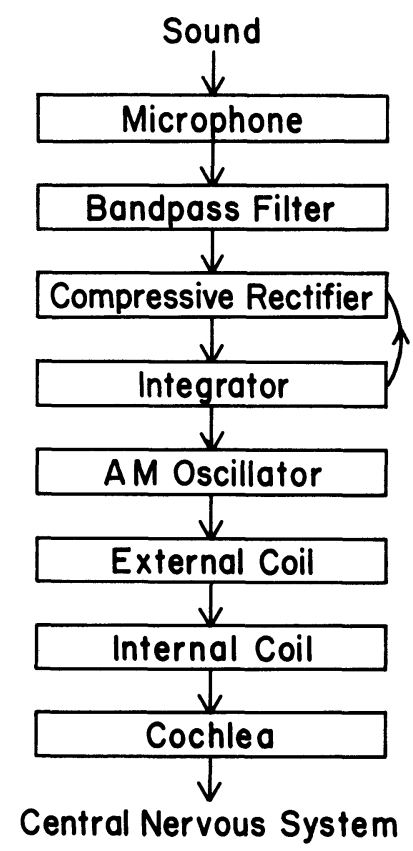

Figure 3. Block diagram of a prosthesis that would introduce temporal dispersion in a manner that approximates the operation of the natural receptor. The output of the microphone is passed through a compressive rectifier that both compresses the dynamic range of the prosthetic signal and gives it a dc component. This signal then goes to an integrator that would remove much of the ac component of the prosthetic response, leaving a temporally dispersed dc component. To fully simulate the natural receptor response, the output of the in tegrator would be fed back to reduce the gain of the compressive rectifier. This would create a prosthetic signal that consisted of an initial transient followed by a more sustained response of lower amplitude. The amount of feedback would influence the degree to which the prosthesis would mediate detection as opposed to recognition. 
degree of temporal dispersion is likely to lead to improvement in the speech recognition abilities of the profoundly deaf.

\section{REFERENCES}

Bilger, R. C., Black, F. O., Hopkinson, N. T., \& Myers, E. N. Implanted auditory prosthesis: An evaluation of subjects presently fitted with cochlear implants. Otolaryngology, 1977, 84, 677-682.

Bilger, R. C., Black, F. O., Hopkinson, N. T., Myers, E. N., Payne, J. L., Stenson, N. R., Vega, A., \& Wolf, R. V. Evaluation of subjects presently fitted with implanted auditory prostheses. Annals of Otology, Rhinology, and Laryngology, 1977, 86(Supp. 38), 1-176.

Corey, D. P., \& Hudspeth, A. J. Ionic basis of the receptor potential in a vertebrate hair cell. Nature, 1979, 281, 675-677.

Djourno, A., \& Eyriès, C. Prosthèse auditive par excitation electrique à distance du nerf sensoriel a l'aide d'un bobinage inclus à demeure. Presse Médicale, 1957, 65, 1417.

Eddington, D. K., Dobelle, W. H., Brackmann, D. E., Mladejovsky, M. G., \& Parkin, J. Place and periodicity pitch by stimulation of multiple scala tympani electrodes in deaf volunteers. American Society for Artificial Internal Organs, Transactions, 1978, 24, 1-5.

Evans, J. R., Gordon, J., Abramov, I., Mladejovsky, M. G. \& Dobelle, W. H. Brightness of phosphenes elicited by electrical stimulation of human visual cortex. Sensory Processes, 1979, 3, 82-94.

Felsten, G., \& Wasserman, G. S. Masking by light in Limulus receptors. Journal of Comparative and Physiological Psychology, 1978, 92, 778-784.

Felsten, G., \& Wasserman, G. S. Masking-induced sensitivity changes in Limulus photoreceptors. Vision Research, 1979, 19, 943-946. (a)

Felsten, G., \& Wasserman, G. S. The photoreceptor sensory code for pattern identification during visual masking. Sensory Processes, 1979, 3, 230-239. (b)

Felsten, G., \& Wasserman, G. S. Visual masking: Mechanisms and theories. Psychological Bulletin, 1980, 88, 329-353.

Felsten, G., \& Wasserman, G. S. The photoreceptor sensory code for perceived duration during visual masking. Physiological Psychology, 1981, 9, 68-76.

Girvin, J. P., Evans, J. R., Dobelle, W. H., Mladejovsky, M. G., Henderson, D. C., Abramov, I., Gordon, J., \& TURKEL, J. Electrical stimulation of human visual cortex: The effect of stimulus parameters on phosphene threshold. Sensory Processes, 1979, 3, 66-81.

Hochmair, E. S., Hochmair-Desoyer, I. J., \& Burian, K. Experience with implanted auditory nerve stimulator. American Society for Artificial Internal Organs, Transactions, 1979, 25, 357-360.

House, W. F., Berliner, K., Crary, W., Graham, M., Luckey, R., Norton, N., Selters, W., Tobin, H., Urban, J., \& WeXLer, M. Cochlear implants. Annals of Otology, Rhinology and Laryngology, 1976, 85(Supp. 27), 1-93.

House, W. F., \& URBAN, J. Long term results of electrode implantation and electronic stimulation of the cochlea in man. Annals of Otology, Rhinology and Laryngology, 1973, 82(2), 504-517.

Kong, K.-L., \& Wasserman, G. S. Changing response measures alters temporal summation in the receptor and spike potentials of the Limulus lateral eye. Sensory Processes, 1978, 2, 21-31. (a)

Kong, K.-L., \& Wasserman, G. S. Temporal summation in the receptor potential of the Limulus lateral eye: Comparison between retinula and eccentric cells. Sensory Processes, 1978, 2, 9-20. (b)

Lawrence, M., \& Johnsson, L.-G. The role of the organ of Corti in auditory nerve stimulation. Annals of Otology, Rhinology and Laryngology, 1973, 82(2), 464-472.

Merzenich, M. M., Michelson, R. P., Pettit, C. R., SChindler, R. A., \& REID, M. Neural encoding of sound sensation evoked by electrical stimulation of the acoustic nerve. Annals of Otology, Rhinology and Laryngology, 1973, 82(2), 486-503.

Michelson, R. P. The results of electrical stimulation of the cochlea in human sensory deafness. Annals of Otology, Rhinology and Laryngology, 1971, 80, 914-919.

Mladejovsky, M. G., Eddington, D. K., Dobelle, W. H., \& Brackmann, D. E. Artificial hearing for the deaf by cochlear stimulation: Pitch modulation and some parametric thresholds. American Society for Artificial Internal Organs, Transactions, 1974, 21, 1-7.

Parasuraman, R., \& Beatty J. Brain events underlying detection and recognition of weak sensory signals. Science, 1980, 210, 80-83.

Pialoux, P., Chouard, C. H., Meyer, B., \& Fugain, C. Indications and results of the multichannel cochlear implant. Acta Otolaryngology, 1979, 87, 185-189.

Russell, I. J., \& Sellick, P. M. The tuning properties of cochlear hair cells. In E. F. Evans \& J. P. Wilson (Eds.), Psychophysics and physiology of hearing. London: Academic Press, 1977.

Russell, I. J., \& SEllick, P. M. Intracellular studies of hair cells in the mammalian cochlea. Journal of Physiology, 1978, 284, 261-290.

Sellick, P. M. Recordings from single receptor cells in the mammalian cochlea. Trends in Neurosciences, 1979, 2, 114-116.

Sellick, P. M., \& Russell, I. J. Two-tone suppression in cochlear hair cells. Hearing Research, 1979, 1, 227-236.

Simmons, F. B. Electrical stimulation of the auditory nerve in man. Archives of Otolaryngology, 1966, 84, 24-76.

Simmons, F. B., Epley, J. M., Lummis, R. C., Guttman, N., Frishkopf, L. S., Harmon, L. D., \& Zwicker, E. Auditory nerve: Electrical stimulation in man. Science, 1965, 148, 104-106.

Simmons, F. B., Mongeon, C. J., Lewis, W. R., \& Huntington, D. A. Electrical stimulation of acoustical nerve and inferior colliculus. Archives of Otolaryngology, 1964, 79, 559-567.

UTTAL, W. R. The psychobiology of sensory coding. New York: Harper \& Row, 1973.

Walloch, R., DeWeese, D., Brummett, R., \& Vernon, J. Electrical stimulation of the inner ear. Annals of Otology, Rhinology and Laryngology, 1973, 82(2), 473-485.

Wasserman, G. S. Limulus psychophysics: Temporal summation in the ventral eye. Journal of Experimental Psychology: General, 1978, 107, 276-286.

WASSERMAN, G. S. Limulus psychophysics: Increment threshold. Perception \& Psychophysics, 1981, 29, 251-260.

Wasserman, G. S., Felsten, G., \& Easland, G. S. Receptor saturation and the psychophysical function. Investigative Ophthalmology and Visual Science, 1978, 17, 155. (Abstract)

Wasserman, G. S., Felsten, G., \& Easland, G. S. The psychophysical function: Harmonizing Fechner and Stevens. Science, 1979, 204, 85-87.

WAsserman, G. S., \& Kong, K. L., Temporal summation in a photoreceptor: Dependence on response magnitude. Vision Research, 1975, 15, 1295-1299.

Wasserman, G. S., Lo, J., \& Easland, G. A modified multiplicative rule describes backward masking in a photoreceptor, Vision Research, 1976, 16, 785-788.

(Received for publication May 29, 1981.) 